\title{
Genomic analysis of Hyphomonas neptunium contradicts 16S rRNA gene-based phylogenetic analysis: implications for the taxonomy of the orders 'Rhodobacterales' and Caulobacterales
}

\author{
Jonathan H. Badger, Jonathan A. Eisen and Naomi L. Ward \\ The Institute for Genomic Research, 9712 Medical Center Dr., Rockville, MD 20850, USA
}

Correspondence

Jonathan H. Badger

jbadger@tigr.org

\begin{abstract}
Hyphomonas neptunium is a marine prosthecate $\alpha$-proteobacterium currently classified as a member of the order 'Rhodobacterales'. Although this classification is supported by $16 \mathrm{~S}$ rRNA gene sequence phylogeny, 23S rRNA gene sequence analysis, concatenated ribosomal proteins, HSP70 and EF-Tu phylogenies all support classifying Hyphomonas neptunium as a member of the Caulobacterales instead. The possible reasons why the 16S rRNA gene sequence gives conflicting results in this case are also discussed.
\end{abstract}

\section{INTRODUCTION}

Hyphomonas neptunium is a prosthecate (having an appendage or 'stalk') $\alpha$-proteobacterium that was isolated from sea water from the harbour at Barcelona, Spain, and was originally described as Hyphomicrobium neptunium (Liefson, 1964). This description was later emended to the current Hyphomonas neptunium on the basis of DNADNA hybridization information (Moore et al., 1984), which showed a closer relationship with Hyphomonas polymorpha (Pongratz, 1957), a marine prosthecate bacterium isolated from a diver with a severe sinus infection, than with other members of the genus Hyphomicrobium. Hyphomonas neptunium also lacks, as does Hyphomonas polymorpha, the ability to utilize $\mathrm{C}_{1}$ molecules as carbon sources, whereas recognized members of Hyphomicrobium have this ability (Moore et al., 1984).

Members of Hyphomonas have an unusual reproductive cycle for prosthecate bacteria; daughter cells are formed on the distal side of the stalk, indicating that DNA, proteins and other cellular components must traverse the stalk (Hirsch, 1974). This trait is shared with numerous marine bacteria originally classified as members of the genus Caulobacter, and the closer relationship between these caulobacters and Hyphomonas to the exclusion of the freshwater caulobacters is also supported by $16 \mathrm{~S}$ rRNA gene sequence phylogeny (Strömpl et al., 2003; Abraham et al., 1999; Stahl et al.,

Published online ahead of print on 3 December 2004 as DOI 10.1099/ ijs.0.63510-0.

Abbreviations: JGI, Joint Genome Institute; TIGR, The Institute for Genomic Research.

Newick tree files and FASTA-format sequence alignments used to generate the trees are available as supplementary information in IJSEM Online.
1992). However, to our knowledge, there have been no studies suggesting a close relationship between freshwater members of Caulobacter (such as Caulobacter crescentus CB15) and Hyphomonas. Currently, Hyphomonas is classified as a member of the order 'Rhodobacterales' (Garrity et al., 2005), whereas the caulobacters are considered members of the eponymous order Caulobacterales (Henrici \& Johnson, 1935). In this paper we show that, although $16 \mathrm{~S}$ rRNA gene sequence analysis supports the current classification, phylogenies based on other markers, such as the $23 \mathrm{~S}$ rRNA gene and many protein sequences, support grouping Hyphomonas as a member of the Caulobacterales. The implications for the taxonomy of the 'Rhodobacterales' and Caulobacterales are discussed, as recent taxonomic recommendations (Stackebrandt et al., 2002) support taking into account phylogenetic analyses from multiple genes.

\section{METHODS}

Data. The complete genome sequence of Hyphomonas neptunium ATCC $15444^{\mathrm{T}}$, comprising a single circular chromosome of $3705611 \mathrm{nt}$ (J. H. Badger and others, unpublished), was sequenced by The Institute for Genomic Research (TIGR) by means of the whole genome shotgun method (Fleischmann et al., 1995). Gene predictions were provided by GLIMMER (Delcher et al., 1999) and functional assignments were produced according to Tettelin et al. (2001). The following complete (or nearly complete) genomes of $\alpha$-proteobacteria were used as sources of sequences for phylogenetic analyses: Agrobacterium tumefaciens C58 (Wood et al., 2001), Anaplasma phagocytophilum HZ (TIGR, unpublished), Bradyrhizobium japonicum USDA 110 (Kaneko et al., 2002), Brucella suis 1330 (Paulsen et al., 2002), C. crescentus CB15 (Nierman et al., 2001), Ehrlichia chaffeensis Arkansas ${ }^{\mathrm{T}}$ (TIGR, unpublished), Mesorhizobium loti MAFF303099 (Kaneko et al., 2000), Neorickettsia sennetsu Miyayama (TIGR, unpublished), Novosphingobium aromaticivorans DSM $12444^{\mathrm{T}}$ [Joint Genome Institute (JGI), unpublished], Rhodobacter capsulatus SB1003 (Integrated Genomics, unpublished), Rhodopseudomonas palustris CGA009 (Larimer et al., 2004), Rhodospirillum 
rubrum ATCC $11170^{\mathrm{T}}$ (JGI, unpublished), Rickettsia conorii Malish $7^{\mathrm{T}}$ (Ogata et al., 2001), Silicibacter pomeroyi DSS- $3^{\mathrm{T}}$ (Moran et al., 2004), Sinorhizobium meliloti 1021 (Capela et al., 2001) and Wolbachia pipientis $w \mathrm{Mel}(\mathrm{Wu}$ et al., 2004). Additionally, the genome of Escherichia coli K-12 MG1655 (Blattner et al., 1997) was used as a source of outgroup sequences. The data from the published genomes were obtained from GenBank; the unpublished data can be obtained from TIGR (http://www.tigr.org/tdb/mdb/mdbinprogress.html), JGI (http://genome.jgi-psf.org/microbial/) and Integrated Genomics (http://ergo.integratedgenomics.com/R_capsulatus.html).

Phylogenetic analysis. Five multiple sequence alignments (see supplementary information available in IJSEM Online) were created for the purpose of phylogenetic inference. These alignments were of: (i) the $16 \mathrm{~S}$ rRNA gene sequence, (ii) the $23 \mathrm{~S}$ rRNA gene sequence, (iii) 30 concatenated ribosomal proteins (totalling approximately 4000 amino acids), (iv) HSP70 proteins and (v) EF-Tu proteins. The rRNA sequences were aligned and masked using the ALIGN sequence tool of the Ribosomal Database Project (Cole et al., 2003), and the protein sequences were aligned using MUSCLE (Edgar, 2004). For all the alignments, bootstrapped neighbour-joining (Saitou \& Nei, 1987) trees were created using the program QUICKTREE (Howe et al., 2002). For the rRNA alignments, bootstrapped maximumlikelihood (Felsenstein, 1981) trees were created using the DNAML program from PHYLIP 3.6b (Felsenstein, 2004), with a $\Gamma$-distribution $(\alpha=0 \cdot 5)$ of rates over four categories of variable sites. For the protein alignments, PROML (also from PHYLIP 3.6b) was used to create maximum-likelihood trees, applying the JTT (Jones et al., 1992) model of substitution, again with a $\Gamma$-distribution $(\alpha=0 \cdot 5)$ of rates over four categories of variable sites. The resulting consensus trees for the protein and rRNA trees were fed into the appropriate program (PROML or DNAML) as user trees in order to obtain the branch lengths. In addition, APIS (J. H. Badger, unpublished), an automated pipeline for phylogenetic inference, was run on all predicted proteins in the Hyphomonas neptunium genome, generating bootstrapped neighbour-joining trees of each protein and its homologues.

\section{RESULTS AND DISCUSSION}

\section{Results of phylogenetic analysis}

Maximum-likelihood analysis of the 16S rRNA gene sequences (Fig. 1; see Table 1 for the GenBank GI numbers

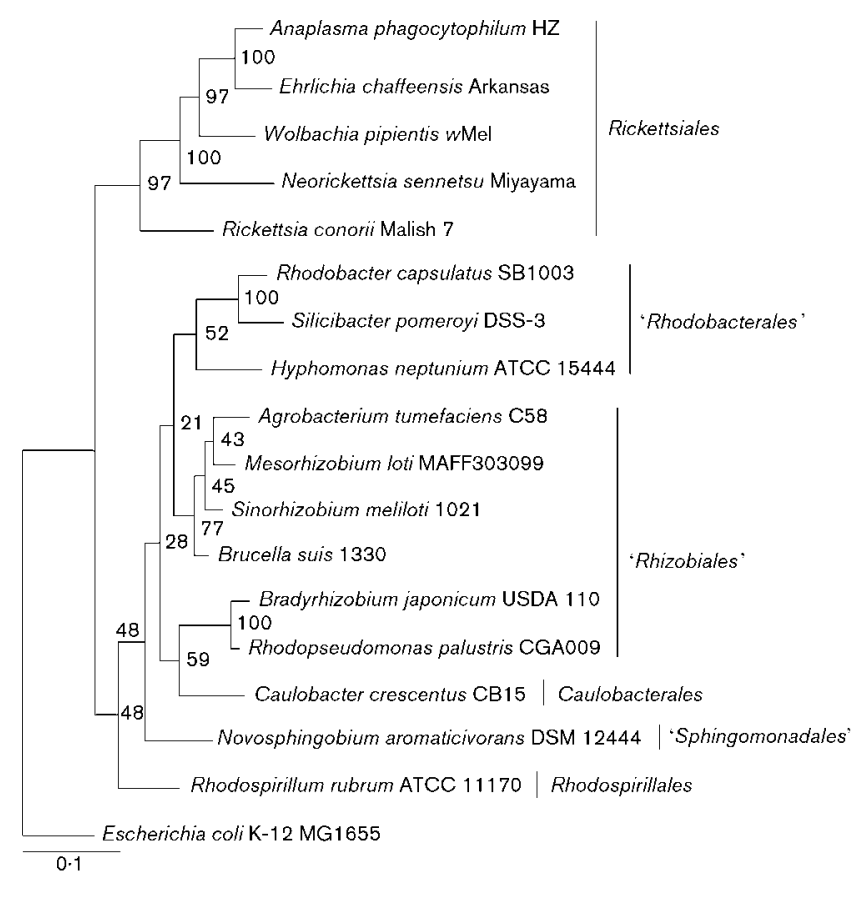

Fig. 1. Maximum-likelihood tree based on 16S rRNA gene sequences from sequenced $\alpha$-proteobacteria. The node labels are bootstrap values (100 replicates). Note the grouping of Hyphomonas neptunium among the 'Rhodobacterales'. See Table 1 for the GenBank Gl numbers and ranges used from published genomes.

and ranges used from published genomes) supports the current classification of Hyphomonas neptunium as a member of the order 'Rhodobacterales', and indeed a similar analysis was probably the reason behind this classification. However, none of the other commonly used phylogenetic markers, including the 23S rRNA gene sequence (Fig. 2a), concatenated ribosomal proteins (Fig. 2b), HSP70 proteins

Table 1. GenBank Gl numbers and sequence ranges (if applicable) from published genomes used in this study

Unpublished genome data were also used for other organisms not listed here.

\begin{tabular}{|c|c|c|c|c|c|}
\hline Organism & \multicolumn{3}{|c|}{ rRNA genes } & $\frac{\text { HSP70 }}{\text { GenBank GI no. }}$ & $\frac{\text { EF-Tu }}{\text { GenBank GI no. }}$ \\
\hline Bradyrhizobium japonicum & 27375111 & $1528226-1529715$ & $1530524-1533397$ & 27375790 & 27380513 \\
\hline Brucella suis & 23499767 & $1108162-1109615$ & $1587832-1584925$ & 23502973 & 17987025 \\
\hline Caulobacter crescentus & 16124256 & $3770203-3771641$ & $3766708-3769496$ & 16124266 & 16125489 \\
\hline Rickettsia conorii & 15891923 & $884601-886108$ & $281797-284557$ & 15892156 & 15892931 \\
\hline Rhodopseudomonas palustris & 39933080 & $5249983-5251464$ & $5246346-5249235$ & 39933410 & 39936346 \\
\hline Silicibacter pomeroyi & 56694928 & $261989-263268$ & 264483-267129 & 56676708 & 56680057 \\
\hline Sinorhizobium meliloti & 15963753 & $81767-83250$ & $84406-87280$ & 15963935 & 15965107 \\
\hline Wolbachia pipientis & 42519920 & $1167943-1169389$ & $182428-185173$ & 42520750 & 42519935 \\
\hline
\end{tabular}




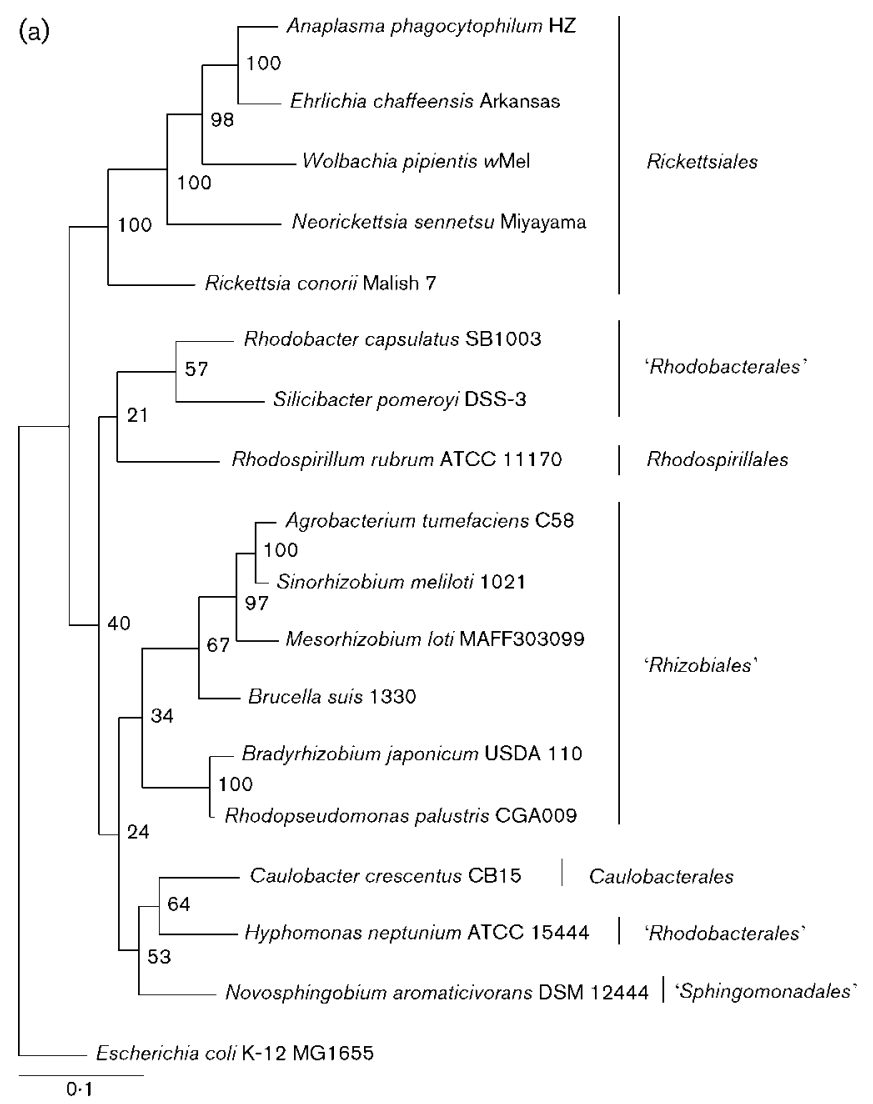

(c)

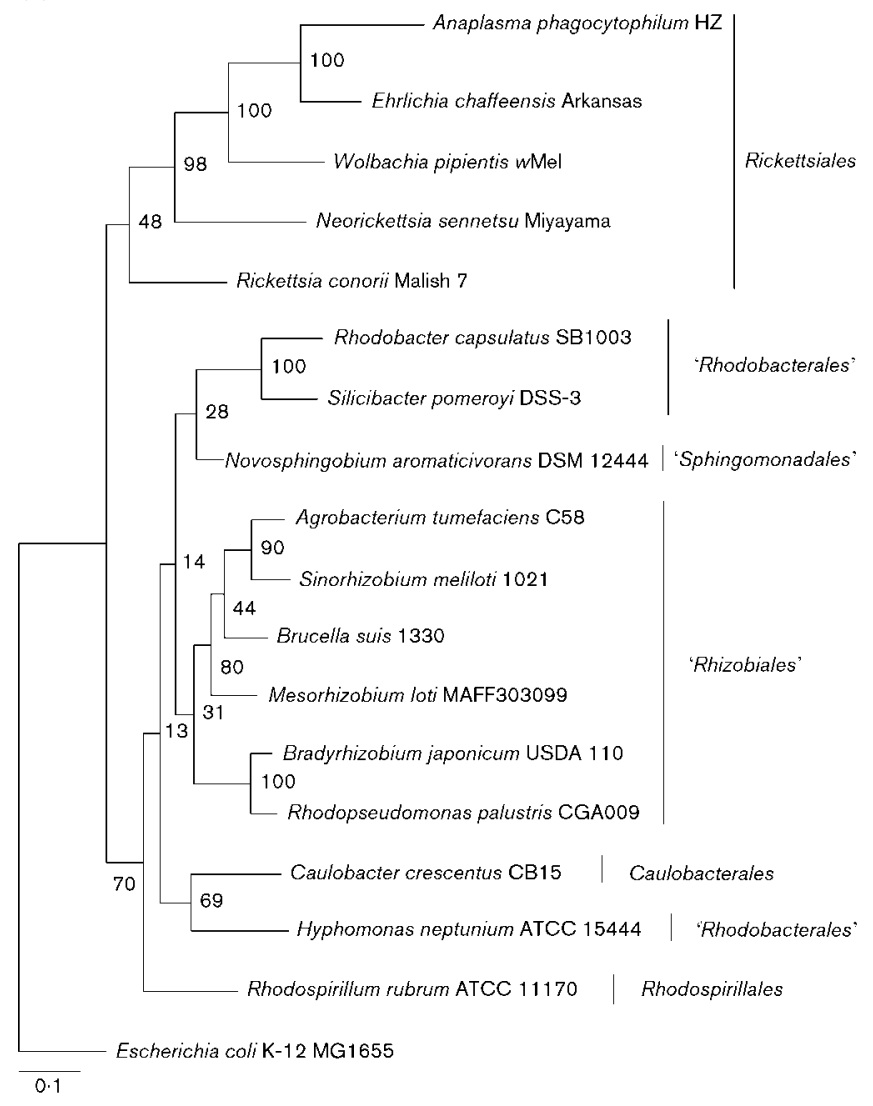

(b)

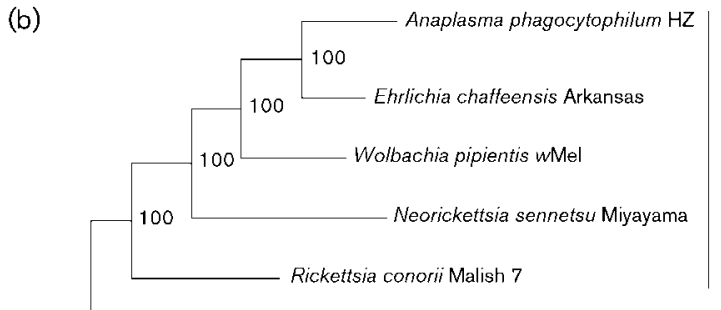

Rickettsiales

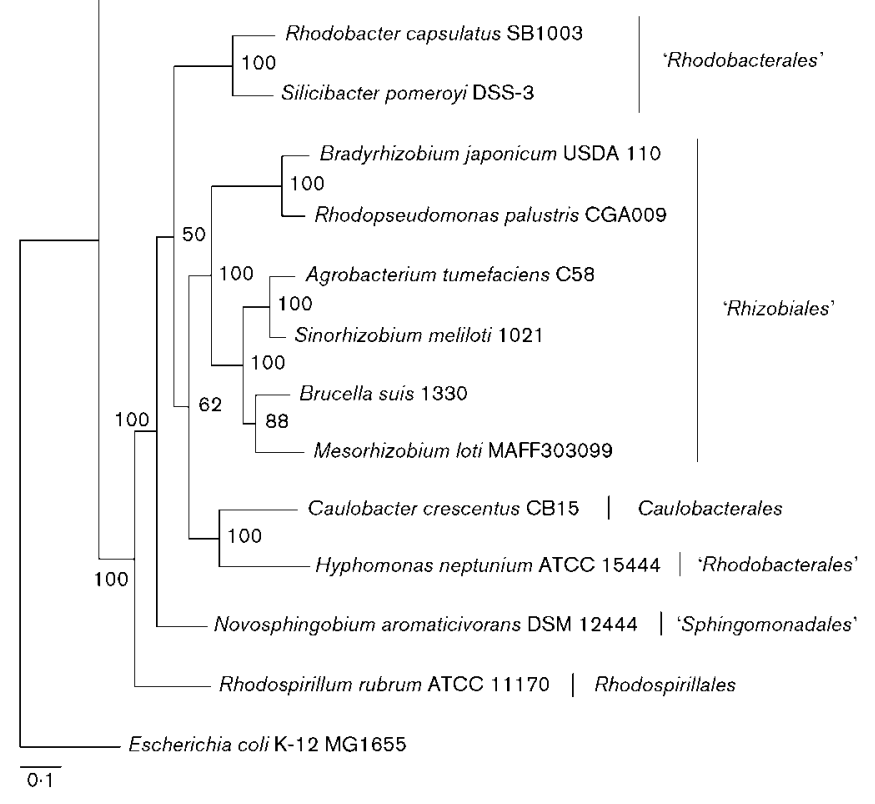

(d)
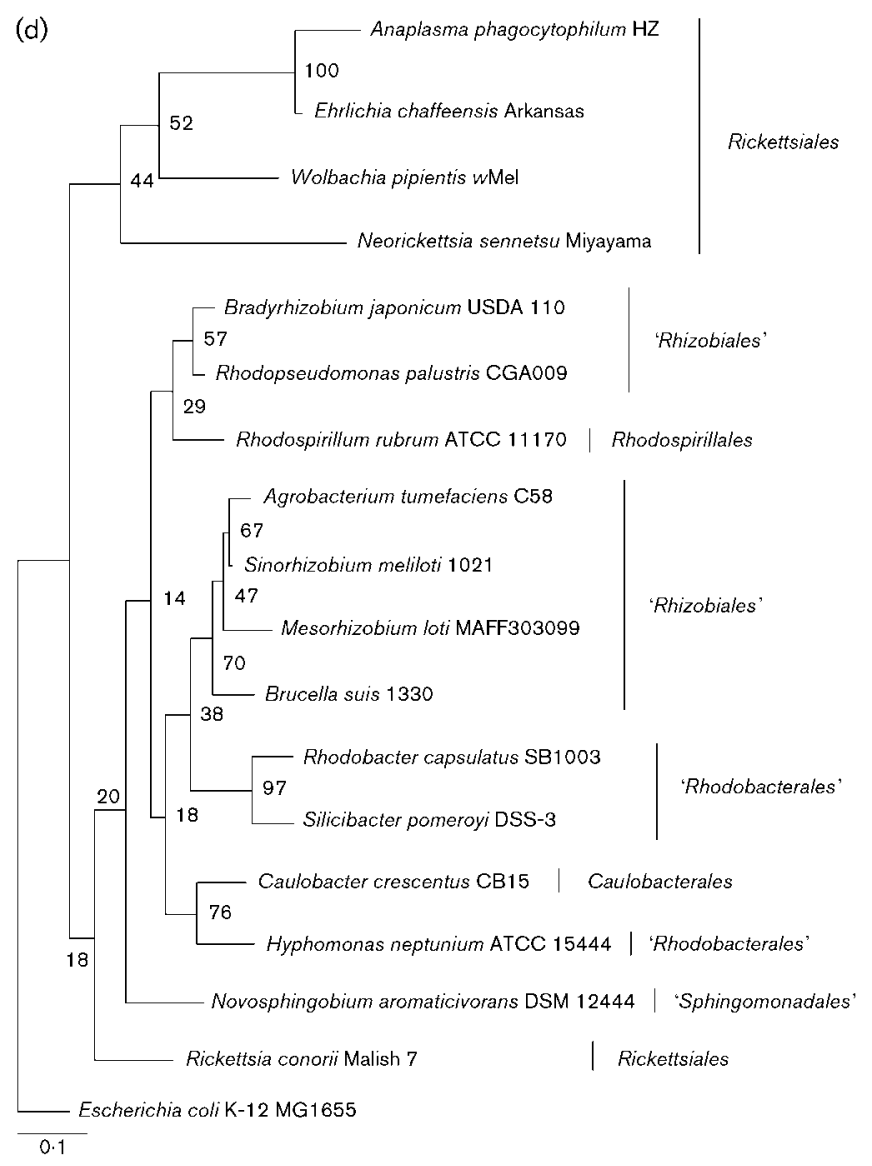
Fig. 2. Maximum-likelihood trees based on $23 S$ rRNA gene sequences (a), 30 concatenated ribosomal proteins ( $L 2$, L3, L4, L5, L13, L14, L15, L16, L17, L20, L21, L22, L23, L24, L27, S2, S3, S4, S6, S7, S8, S10, S11, S12, S13, S14, S15, S16, $\mathrm{S} 17$ and S19) (b), HSP70 proteins (c) and EF-Tu proteins (d) from sequenced $\alpha$-proteobacteria. Node labels are bootstrap values (100 replicates). Note the grouping of Hyphomonas neptunium with C. crescentus in each tree. See Table 1 for the GenBank Gl numbers and ranges used from published genomes.

(Fig. 2c) and EF-Tu proteins (Fig. 2d), supports this classification. Instead, they support a relationship between Hyphomonas neptunium and C. crescentus. A similar relationship was seen in the trees generated by APIS, in which over $30 \%$ of the Hyphomonas neptunium proteins had a protein from $C$. crescentus as their closest relative, as opposed to only $6 \%$ that grouped with a member of the 'Rhodobacterales'. Most notably, the flagellar and other chemotaxis proteins tend to show a closer relationship to those of Silicibacter pomeroyi than to those of C. crescentus, although this may be because the Hyphomonas neptunium versions of these proteins are quite divergent from even their closest known homologues.

The bootstrap support values for the clades of interest in these trees vary. The 16S rRNA gene sequence tree (Fig. 1) shows only weak (52\%) support for the currently accepted grouping of Hyphomonas neptunium among the 'Rhodobacterales', and the $23 \mathrm{~S}$ rRNA gene sequence tree (Fig. 2a) shows only somewhat stronger $(64 \%)$ support for the alternative classification among the Caulobacterales. The concatenated ribosomal protein tree (Fig. 2b), however, shows excellent support $(100 \%)$ for this alternative classification, and levels of support from the HSP70 (Fig. 2c) and EF-Tu (Fig. 2d) trees for the alternative classification are strong as well (69 and $76 \%$, respectively).

In order to explore further the degree of support that each tree has for the alternative hypotheses, Kishino-HasegawaTempleton tests (Kishino \& Hasegawa, 1989; Templeton, 1983) were performed to determine whether each alignment preferred the $16 \mathrm{~S}$ or the $23 \mathrm{~S}$ rRNA gene sequence tree. For each alignment, if the mean of the log-likelihood differences between the $16 \mathrm{~S}$ and $23 \mathrm{~S}$ tree across the sites was greater than 1.96 standard deviations, then the more likely tree was judged to be significantly preferred. The $23 \mathrm{~S}$ alignment and all protein alignments except for the EF-Tu alignment significantly preferred the $23 \mathrm{~S}$ tree; although the $16 \mathrm{~S}$ alignment preferred the $16 \mathrm{~S}$ tree and the EF-Tu alignment preferred the $23 \mathrm{~S}$ tree, they did not do so at a statistically significant level.

\section{Evolutionary implications}

Although the discovery of conflict between 16S rRNA gene sequence and protein trees is not in itself a novel finding (e.g. Doolittle, 1999; Gupta \& Golding, 1993), in general such studies either try to argue for the superiority over rRNA of a single favourite marker protein [as was done by Gupta \& Golding (1993) for HSP70] or claim that rampant horizontal gene transfer has destroyed all phylogenetic signal (as in Doolittle, 1999). To our knowledge, this is the first study in which numerous proteins, together with the $23 \mathrm{~S}$ rRNA gene, consistently yield a single alternative orderlevel classification for a bacterial species.

What can be the cause of this difference? One possibility is horizontal gene transfer of the $16 \mathrm{~S}$ rRNA gene. Horizontal gene transfer of the 16S rRNA gene has been suggested as an explanation for patterns seen at the genus level (e.g. Schouls et al., 2003; Parker et al., 2002), and artificially induced transfer of the 16S and 23S rRNA genes between Escherichia coli and Salmonella typhimurium has been demonstrated experimentally (Asai et al., 1999). The presence of only a single copy of the 16S rRNA gene in Hyphomonas neptunium would also make horizontal gene transfer of the $16 \mathrm{~S}$ rRNA gene possibly easier than in most bacteria. Another possibility could be long-branch attraction (Felsenstein, 1978) in the tree based on 16S rRNA gene sequence analysis, but, as shown in Figs 1 and 2(a), the branch lengths appear not to be particularly long.

In addition to being supported by all the sequence data except that for the 16S rRNA gene, a classification of Hyphomonas as a member of the Caulobacterales also makes sense from the standpoint of phenotypic characters. Like Caulobacter, members of Hyphomonas are aerobic, dimorphic, prosthecate bacteria. In the current classification scheme, these traits either would have had to evolve independently in the 'Rhodobacterales' or would have to have been present in a common ancestor of the 'Rhodobacterales' and Caulobacterales and then been lost by the majority of the members of the 'Rhodobacterales'.

Current guidelines for the rearrangement of higher order taxa preclude the transfer of a genus without analysis of the type species (Sneath, 1992). Given that the type species of Hyphomonas is Hyphomonas polymorpha rather than Hyphomonas neptunium, a transfer of the genus Hyphomonas is not presently possible. However, given the close phylogenetic relationship between these two species [according to the 16S rRNA gene sequence and DNADNA hybridization studies in Weiner et al. (2000) they are among the most closely related of the eight recognized Hyphomonas species], we expect that future work on Hyphomonas polymorpha will support such a transfer.

Additionally, there exist several genera of prosthecate budding bacteria (Hirschia, Maricaulis and Oceanicaulis) that are immediate relatives of Hyphomonas according to 16S rRNA gene sequence phylogeny (Strömpl et al., 2003). Assuming that this is not an artefact of $16 \mathrm{~S}$ rRNA gene 
sequence phylogeny, these genera would have to be transferred into the Caulobacterales along with Hyphomonas. Further work, including genome sequencing of the type species of representatives of these genera, would provide valuable data that will help to clarify the relationships among the prosthecate $\alpha$-proteobacteria, and possibly support the transfer of Hyphomonas.

\section{ACKNOWLEDGEMENTS}

We thank Gary Olsen for valuable discussion, and Hervé Tettelin for the use of prepublication data from Anaplasma phagocytophilum, Ehrlichia chaffeensis and Neorickettsia sennetsu. We also thank the US Department of Energy Joint Genome Institute for the use of their sequence data from Novosphingobium aromaticivorans and Rhodospirillum rubrum prior to publication and Integrated Genomics for the use of their Rhodobacter capsulatus genome data. The sequencing and analysis of Hyphomonas neptunium was funded by National Science Foundation Award 0237224 to Timothy Hoover, Yves Brun and N.L.W. In addition, the phylogenetic analysis was supported in part by NSF Tree of Life Grant 0228651 to J.A.E., N. L.W. and Karen Nelson.

\section{REFERENCES}

Abraham, W. R., Strömpl, C., Meyer, H. \& 8 other authors (1999). Phylogeny and polyphasic taxonomy of Caulobacter species. Proposal of Maricaulis gen. nov. with Maricaulis maris (Poindexter) comb. nov. as the type species, and emended description of the genera Brevundimonas and Caulobacter. Int J Syst Bacteriol 49, 1053-1073.

Asai, T., Zaporojets, D., Squires, C. \& Squires, C. L. (1999). An Escherichia coli strain with all chromosomal rRNA operons inactivated: complete exchange of rRNA genes between bacteria. Proc Natl Acad Sci U S A 96, 1820-1822.

Blattner, F. R., Plunkett, G., Bloch, C. A. \& 14 other authors (1997). The complete genome sequence of Escherichia coli K-12. Science 277, 1453-1474.

Capela, D., Barloy-Hubler, F., Gouzy, J. \& 25 other authors (2001). Analysis of the chromosome sequence of the legume symbiont Sinorhizobium meliloti strain 1021. Proc Natl Acad Sci U S A 98, 9877-9882.

Cole, J. R., Chai, B., Marsh, T. L. \& 8 other authors (2003). The Ribosomal Database Project (RDP-II): previewing a new autoaligner that allows regular updates and the new prokaryotic taxonomy. Nucleic Acids Res 31, 442-443.

Delcher, A. L., Harmon, D., Kasif, S., White, O. \& Salzberg, S. L. (1999). Improved microbial gene identification with GLIMMER. Nucleic Acids Res 27, 4636-4641.

Doolittle, W. F. (1999). Phylogenetic classification and the universal tree. Science 284, 2124-2129.

Edgar, R. C. (2004). MUSCLE: multiple sequence alignment with high accuracy and high throughput. Nucleic Acids Res 32, 1792-1797.

Felsenstein, J. (1978). Cases in which parsimony and compatibility methods will be positively misleading. Syst Zool 27, 401-410.

Felsenstein, J. (1981). Evolutionary trees from DNA sequences: a maximum likelihood approach. J Mol Evol 17, 368-376.

Felsenstein, J. (2004). PHYLIP (Phylogeny Inference Package), version 3.6b. Distributed by the author. Department of Genetics, University of Washington, Seattle, USA.
Fleischmann, R. D., Adams, M. D., White, O. \& 37 other authors (1995). Whole-genome random sequencing and assembly of Haemophilus influenzae Rd. Science 269, 279-291.

Garrity, G. M., Bell, J. A. \& Lilburn, T. (2005). Order Rhodobacterales ord. nov. In Bergey's Manual of Systematic Bacteriology, 2nd edn, vol. 2. New York: Springer (in press).

Gupta, R. S. \& Golding, G. B. (1993). Evolution of HSP70 gene and its implications regarding relationships between archaebacteria, eubacteria, and eukaryotes. J Mol Evol 37, 573-582.

Henrici, A. T. \& Johnson, D. (1935). Stalked bacteria, a new order of Schizomycetes. J Bacteriol 29, 3-4.

Hirsch, P. (1974). Budding bacteria. Annu Rev Microbiol 28, 391-444.

Howe, K., Bateman, A. \& Durbin, R. (2002). QUICKTREE: building huge neighbour-joining trees of protein sequences. Bioinformatics 18, 1546-1547.

Jones, D. T., Taylor, W. R. \& Thornton, J. M. (1992). The rapid generation of mutation data matrices from protein sequences. Comput Appl Biosci 8, 275-282.

Kaneko, T., Nakamura, Y., Sato, S. \& 21 other authors (2000). Complete genome structure of the nitrogen-fixing symbiotic bacterium Mesorhizobium loti. DNA Res 7, 331-338.

Kaneko, T., Nakamura, Y., Sato, S. \& 14 other authors (2002). Complete genomic sequence of nitrogen-fixing symbiotic bacterium Bradyrhizobium japonicum USDA 110. DNA Res 9, 189-197.

Kishino, H. \& Hasegawa, M. (1989). Evaluation of the maximum likelihood estimate of the evolutionary tree topologies from DNA sequence data and the branching order in Hominoidea. $J$ Mol Evol 29, 170-179.

Larimer, F. W., Chain, P., Hauser, L. \& 16 other authors (2004). Complete genome sequence of the metabolically versatile photosynthetic bacterium Rhodopseudomonas palustris. Nat Biotechnol 22, 55-61.

Liefson, E. (1964). Hyphomicrobium neptunium sp. nov. Antonie van Leeuwenhoek 30, 249-256.

Moore, R. L., Weiner, R. M. \& Gebers, R. (1984). Genus Hyphomonas Pongratz 1957 nom. rev. emend., Hyphomonas polymorpha Pongratz 1957 nom. rev. emend., and Hyphomonas neptunium (Liefson 1964) comb nov. emend. (Hyphomicrobium neptunium). Int J Syst Bacteriol 34, 71-73.

Moran, M. A., Buchan, A., Gonzalez, J. M. \& 32 other authors (2004). Genome sequence of Silicibacter pomeroyi reveals adaptations to the marine environment. Nature 432, 910-913.

Nierman, W. C., Feldblyum, T. V., Laub, M. T. \& 35 other authors (2001). Complete genome sequence of Caulobacter crescentus. Proc Natl Acad Sci U S A 98, 4136-4141.

Ogata, H., Audic, S., Renesto-Audiffren, P. \& 8 other authors (2001). Mechanisms of evolution in Rickettsia conorii and $R$. prowazekii. Science 293, 2093-2098.

Parker, M. A., Lafay, B., Burdon, J. J. \& van Berkum, P. (2002). Conflicting phylogeographic patterns in rRNA and nifD indicate regionally restricted gene transfer in Bradyrhizobium. Microbiology 148, 2557-2565.

Paulsen, I. T., Seshadri, R., Nelson, K. E. \& 27 other authors (2002). The Brucella suis genome reveals fundamental similarities between animal and plant pathogens and symbionts. Proc Natl Acad Sci U S A 99, 13148-13153.

Pongratz, E. (1957). D’une bactérie pediculé isolé d'un pus de sinus. Schweiz Z Allg Pathol Bakteriol 20, 593-608 (in French).

Saitou, N. \& Nei, M. (1987). The neighbor-joining method: a new method for reconstructing phylogenetic trees. Mol Biol Evol 4, $406-425$. 
Schouls, L. M., Schot, C. S. \& Jacobs, J. A. (2003). Horizontal transfer of segments of the 16S rRNA genes between species of the Streptococcus anginosus group. J Bacteriol 185, 7241-7246.

Sneath, P. H. A. (1992). International Code of Nomenclature of Bacteria (1990 Revision). Bacteriological Code. Washington, DC: American Society for Microbiology.

Stackebrandt, E., Frederiksen, W., Garrity, G. M. \& 10 other authors (2002). Report of the ad hoc committee for the reevaluation of the species definition in bacteriology. Int J Syst Evol Microbiol 52, 1043-1047.

Stahl, D. A., Key, R., Flesher, B. \& Smit, J. (1992). The phylogeny of marine and freshwater caulobacters reflects their habitat. J Bacteriol 174, 2193-2198.

Strömpl, C., Hold, G. L., Lünsdorf, H., Graham, J., Gallacher, S., Abraham, W. R., Moore, E. R. B. \& Timmis, K. N. (2003). Oceanicaulis alexandrii gen. nov., sp. nov., a novel stalked bacterium isolated from a culture of the dinoflagellate Alexandrium tamarense (Lebour) Balech. Int J Syst Evol Microbiol 53, 1901-1906.
Templeton, A. R. (1983). Phylogenetic inference from restriction endonuclease cleavage site maps with particular reference to the evolution of humans and the apes. Evolution 37, 221-244.

Tettelin, H., Nelson, K. E., Paulsen, I. T. \& 36 other authors (2001). Complete genome sequence of a virulent isolate of Streptococcus pneumoniae. Science 293, 498-506.

Weiner, R. M., Melick, M., O'Neill, K. \& Quintero, E. (2000). Hyphomonas adhaerens sp. nov., Hyphomonas johnsonii sp. nov. and Hyphomonas rosenbergii sp. nov., marine budding and prosthecate bacteria. Int J Syst Evol Microbiol 50, 459-469.

Wood, D. W., Setubal, J. C., Kaul, R. \& 48 other authors (2001). The genome of the natural genetic engineer Agrobacterium tumefaciens C58. Science 294, 2317-2323.

Wu, M., Sun, L. V., Vamathevan, J. \& 27 other authors (2004). Phylogenomics of the reproductive parasite Wolbachia pipientis wMel: a streamlined genome overrun by mobile genetic elements. PLoS Biol 2, E69. 